\section{Nutrient intakes and impact of fortified breakfast cereals in schoolchildren} Helene McNulty, Jill Eaton-Evans, Gordon Cran, Gregory Woulahan, Colin Boreham,
J Maurice Savage, Reginald Fletcher, John J Strain

\begin{abstract}
Objective-To report micronutrient intakes in Northern Ireland schoolchildren, and to establish the contribution of fortified breakfast cereal to overall nutrient intakes and achievement of current dietary recommendations.

Design-Analysis of dietary intakes and physical characteristics of participants in a randomly selected $2 \%$ population sample of 1015 schoolchildren aged 12 and 15 years in Northern Ireland during the 1990/1 school year.

Main outcome measures-Dietary intakes, physical characteristics, and their association with consumption of fortified breakfast cereal.

Results-Mean micronutrient intakes were generally adequate with the exception of low intakes of folate (boys and girls) and iron (girls). Fortified breakfast cereals, consumed by a high proportion ( $94 \%$ boys; $83 \%$ girls) of the sample, were associated with higher daily intakes of most micronutrients and fibre and with a macronutrient profile consistent with current nutritional recommendations. Appreciable proportions of subjects who did not consume fortified breakfast cereals had daily intakes that fell below the lower reference nutrient intake for riboflavin, niacin, folate, vitamin B-12, and iron (girls).

Conclusions-The results demonstrate the potential of fortification in contributing to micronutrient intakes of schoolchildren, particularly where requirements are high, or for those on marginal diets of low nutritional quality.

(Arch Dis Child 1996;75:474-481)
\end{abstract}

Keywords: fortification, micronutrients, dietary intakes, Northern Ireland schoolchildren.

Diet in childhood is considered to be an important factor in the development of disease in later life. Not only are eating patterns believed to be established in childhood, but many diet related disease processes may start in childhood. A number of epidemiological stud- ies in different populations have demonstrated 'tracking' of risk factors for chronic disease, the phenomenon whereby those individuals with plasma lipids, blood pressure, and body mass index in the upper end of the distribution in childhood appear to remain so during adulthood. ${ }^{2}$ Thus nutritional targets such as those set out in the government strategy paper The Health of the Nation have directed attention to the diets of children and adolescents acknowledging that many of the effects of diet are long term. ${ }^{3}$ More recent reports have re-emphasised that nutritional recommendations for the prevention of chronic disease in adulthood are applicable in full from the age of 5 years onwards throughout childhood. ${ }^{4}$ Adolescence is generally considered a nutritionally vulnerable period, as it is a time of significant change in lifestyle, food habits, and physiology. Of particular concern is the maintenance of healthy body weight, avoidance of excess fat intakes, and achievement of adequate intake of micronutrients.

Recent surveys of schoolchildren in the UK have confirmed a trend away from conventional family meal times towards dietary habits that are characterised by informal eating and frequent snacking, ${ }^{56}$ with snack foods contributing up to one third of total energy intakes. ${ }^{7}$ Breakfast cereals feature prominently in the diets of children and adolescents, not only at breakfast but also as snack foods throughout the day. ${ }^{8}$ The majority of breakfast cereals have been fortified with a range of vitamins and iron on a voluntary basis for many years, but the effectiveness of such wide ranging fortification in the diets of schoolchildren in the UK has not been confirmed in a population study. Fortification may be particularly important in the diets of at risk subgroups, such as female adolescents consuming 'slimming diets' to lose weight (estimated to be up to $60 \%$ of girls aged 11-18 years), ${ }^{9}$ or where evidence for increased requirement of a specific nutrient (for example folic acid in the prevention of neural tube defects) has resulted in the generation of official recommendations ${ }^{10}$ at levels far in excess of those provided by the national diet.

The aim of the present study was to report micronutrient intakes in a random sample of Northern Ireland schoolchildren aged 12 and 
15, and to establish the extent to which the consumption of fortified breakfast cereal by this population contributes to overall nutrient intakes and achievement of current dietary recommendations.

\section{Methods}

SUBJECTS

The dietary and other data reported here were collected as part of a larger study of coronary risk factors in Northern Ireland schoolchildren. A detailed description of the sampling procedure used including reasons for nonresponse, along with information on the nature and extent of factors associated with coronary risk in schoolchildren in Northern Ireland, has been published previously. ${ }^{11}$ The sampling procedure of the original study was designed to select a sample of approximately 250 children from each of the following age-sex groups: 12 year old boys, 12 year old girls, 15 year old boys, 15 year old girls. Account was taken of geographical spread and the different categories of schools in Northern Ireland. The number amounted to a $2 \%$ random sample of each of the two age populations in Northern Ireland. The procedure allowed for nonresponse and drop-outs by increasing the target numbers by approximately $20 \%$. An overall response rate of $78 \%$ resulted in a total of 1015 subjects being tested. Prior ethical approval for the main study was secured from the Queen's University of Belfast ethical committee, and written consent was obtained from the parent or guardian of each participating subject. ${ }^{11}$

The test protocol included a medical examination during which height and weight were determined from which body mass index was calculated. Skinfold thicknesses were obtained from four sites for the estimation of body composition. ${ }^{12}$ Blood pressure was measured twice from the right arm as previously described. ${ }^{11}$ Cardiorespiratory fitness was determined by the 20 metre endurance shuttle run, ${ }^{13}$ and converted to predicted maximal oxygen uptake score using linear regression. ${ }^{14}$ Estimations of total cholesterol concentration (enzymatic technique: CHOD-PAP, Boehringer Mannheim) were carried out on nonfasting venous blood samples obtained under local anaesthesia and separated within four hours.

\section{DIETARY METHODOLOGY}

Full details of the dietary methodology, including the quality control measures undertaken to optimise consistency of procedures, have been published elsewhere. ${ }^{15}$ Briefly, dietary data were obtained by three trained field workers during an open ended interview (lasting approximately one hour) using the diet history method $^{16}$ to record habitual meal and snack consumption, in conjunction with a food photographic atlas ${ }^{17}$ and published data to estimate food portion sizes. ${ }^{18}$ Recorded food intakes were converted into energy and nutrient intakes using a computerised dietary analysis program as previously described. ${ }^{15}$

Reported food intakes by this dietary methodology have been shown to be more representative of energy intake than those obtained by the weighed dietary record when both methods were independently validated, using doubly labelled water as a measure of energy expenditure, in a sample of schoolchildren of 12 and 15 years. ${ }^{19}$ However, in order to identify a small number of subjects whose reported intakes were likely to be underrepresentative of actual energy (and, in turn, micronutrient) intake based on fundamental principles of energy physiology, a statistically derived lower cut off value for ratios of reported energy intake to calculated basal metabolic rate (EI:BMR, 1.14) ${ }^{20}$ was applied; any individual with an EI:BMR ratio of less than this value may be classified as an under-reporter of food intake. When this cut off point was employed in a previous analysis of this population, ${ }^{15}$ under-reporting was identified in $13.4 \%, 7.8 \%, 6.0 \%$, and $5.6 \%$ of 15 year old girls, 12 year old girls, 12 year old boys, and 15 year old boys respectively. The same principle can be applied to identify overreporters of food intake by using an upper cut off value of EI:BMR. The use of these cut off values based on multiples of BMR to remove those with doubtful food intakes is still a matter of debate and it is difficult to derive an objective upper cut off value. ${ }^{21}$ Thus, in the presentation of micronutrient intake, all data were retained and analysed by methods robust to values in the tails of the nutrients being studied (see under statistical methods) as previously used in the publication of macronutrient intake in this population. ${ }^{15}$ However, for comparison of intakes according to fortified breakfast cereal consumption level, and for examination of data according to achievement of dietary reference values, it was felt important to exclude those subjects classified as underreporters since the correlation of total nutrient intake with total energy intake for most micronutrients means that under-reporting overestimates the presence of low intakes.

\section{STATISTICAL METHODS}

Mean values for micronutrients reported in table 1 are medians with 25 th and 75 th centiles. Statistical comparisons between subject age-sex groups are based on the Kolmogorov-Smirnov two sample test at a 5\% significance level. Values with respect to fortified breakfast cereal consumption are reported (tables 2,4, and 5) as means with $95 \%$ confidence intervals. Fortified breakfast cereal consumption categories are $0,1-20,1-40$, and $>40 \mathrm{~g} /$ day which correspond to non-consumer, consumption of breakfast cereal two to three times weekly, once daily, and more than once daily respectively. Statistical comparisons between levels of breakfast cereal consumption are based on one way analysis of variance with least significant difference test (in some cases a square root or $\log$ transformation of the data was employed as appropriate). In tables 2,4 , and 5 a large number of hypothesis tests, each at the $5 \%$ level, are reported. Because of the problem of multiple testing, the assertion of a significant difference should be treated with caution; the existence of a statistically signifi- 
Table 1 Median daily intake of micronutrients in Northern Ireland schoolchildren. Median values with 25th and 75 th centiles are given in parentheses

\begin{tabular}{|c|c|c|c|c|}
\hline & \multicolumn{2}{|l|}{ Boys } & \multicolumn{2}{|l|}{ Girls } \\
\hline & 12 years $(n=251)$ & 15 years $(n=252)$ & 12 years $(n=258)$ & 15 years $(n=254)$ \\
\hline Thiamin (mg) & $1.38(1.08,1.65)$ & $1.59(1.27,1.87)$ & $1.09(0.92,1.37)$ & $1.04(0.86,1.27)$ \\
\hline Riboflavin (mg) & $1.93(1.44,2.41)$ & $2.24(1.71,2.86)$ & $1.51(1.18,1.83)$ & $1.29(1.01,1.71)$ \\
\hline Niacin (mg) & $33.0(27.6,39.8)$ & $39.8(33.0,47.4)$ & $27.0(22.7,32.4)$ & $26.7(22.0,32.7)$ \\
\hline Vitamin B-6 (mg) & $1.91(1.48,2.34)$ & $2.22(1.82,2.63)$ & $1.58(1.31,1.89)$ & $1.49(1.23,1.86)$ \\
\hline Vitamin B-12 $(\mu \mathrm{g})$ & $3.4(2.6,4.3)$ & $3.9(3.1,5.3)$ & $2.6(2.0,3.3)$ & $2.5(1.7,3.2)$ \\
\hline Folate $(\mu \mathrm{g})$ & $129(101,154)$ & $156(123,193)$ & $114(95,141)$ & $121(98,155)$ \\
\hline Retinol $(\mu \mathrm{g})$ & $386(260,513)$ & $465(337,624)$ & $295(225,400)$ & $304(219,407)$ \\
\hline Carotene $(\mu \mathrm{g})$ & $1589(732,2661)$ & $1523(707,2664)$ & $1475(865,2454)$ & $1416(806,2484)$ \\
\hline Vitamin C (mg) & $61.7(43.8,90.9)$ & $73.2(50.9,102.4)$ & $68.0(44.0,97.6)$ & $71.1(49.3,114.8)$ \\
\hline Vitamin D $(\mu \mathrm{g})$ & $1.74(1.11,2.80)$ & $2.18(1.29,3.41)$ & $1.67(0.99,2.32)$ & $1.66(0.96,2.73)$ \\
\hline Vitamin E ( $\mu \mathrm{g})$ & $4.9(3.8,6.5)$ & $5.9(4.5,7.7)$ & $4.9(3.7,6.5)$ & $5.5(4.2,7.2)$ \\
\hline Iron (mg) & $12.5(10.6,15.6)$ & $15.0(12.7,17.6)$ & $10.6(9.0,13.0)$ & $10.9(8.6,13.1)$ \\
\hline Zinc (mg) & $8.6(7.3,10.3)$ & $10.3(8.4,12.7)$ & $7.3(6.0,8.9)$ & $7.4(5.9,9.0)$ \\
\hline Copper (mg) & $1.7(1.4,2.0)$ & $1.9(1.7,2.4)$ & $1.4(1.2,1.7)$ & $1.4(1.2,1.8)$ \\
\hline
\end{tabular}

cant difference does not necessarily infer a practically important difference. The reporting of such differences was, however, considered to be useful to the reader. The least significant difference test was carried out only when the variance ratio in the analysis of variance was significant at $\mathrm{p}<0.05$.

When the EI:BMR cut off ratio of 1.14 was employed to exclude the subjects who were classified as under-reporters of actual food intake, an edited sample comprising boys aged 12 years $(n=237)$ and 15 years $(n=238)$ and girls aged 12 years $(n=238)$ and 15 years $(n=221)$ was obtained. This edited sample was used in all analyses except for the median (25th and 75 th centile) values reported in table 1 (see under dietary methodology).

\section{Results}

Median (25th and 75th centiles) daily intakes of micronutrients for each age-sex group are reported in table 1 . The 15 year old boys had significantly $(p<0.001)$ higher intakes than the 12 year old boys who, in turn, had significantly $(p<0.001)$ higher intakes than girls of thiamin, riboflavin, niacin, vitamin B-6, vitamin B-12, retinol, iron, zinc, and copper. The 15 year old boys also had significantly higher intakes than the 12 year old boys of folate and vitamin $\mathrm{E}$. The latter, in turn, had a significantly $(p<0.001)$ higher intake of folate than the 12 year old girls. Intakes of folate, vitamin $C$, and vitamin $\mathrm{E}$ by the older girls were also significantly $(p<0.05)$ higher than the younger girls. The intake of vitamin $\mathrm{D}$ in the 15 year old boys was significantly higher than in the 12 year old boys $(p<0.01)$ and also higher than in the 12 year old girls $(p<0.001)$.

A high proportion of Northern Ireland schoolchildren reported eating fortified breakfast cereal (95 and $92 \%$ of males aged 12 and 15 years; 87 and $78 \%$ of females aged 12 and 15 years respectively). Of those consuming breakfast cereal, a substantial proportion ( $84 \%$ of male consumers, $60 \%$ of female consumers) consumed more than $20 \mathrm{~g} /$ day-that is, at least one serving daily.

Estimates of daily intake of micronutrients traditionally added to breakfast cereals, along with calcium and zinc at four levels of consumption of fortified breakfast cereal, are given in table 2 . Intakes of thiamin, riboflavin, and niacin increased with increasing consumption of breakfast cereal in all sex-age groups. Vitamin B-6 intake was significantly different between the breakfast cereal consumption groups only in 12 year old girls who consumed more than $40 \mathrm{~g} /$ day fortified breakfast cereal. In general, higher breakfast cereal consumption was associated with higher vitamin B-12 intake, except for boys aged 12 years. Folate intake significantly increased with increasing consumption of fortified breakfast cereal in the younger adolescents and was greater in girls aged 15 who consumed more than $20 \mathrm{~g}$ /day breakfast cereal and in 15 year old boys who consumed more than $40 \mathrm{~g} /$ day breakfast cereal, compared with non-consumers or those consuming lower levels. In general, higher breakfast cereal consumption was associated with higher iron intake in all age-sex groups except 15 year old boys. Calcium intake increased with increasing breakfast cereal consumption in all age-sex groups. Zinc intake was higher at breakfast cereal consumption levels greater than $20 \mathrm{~g} /$ day in 15 year old boys and girls, and greater than $40 \mathrm{~g} /$ day in 12 year old boys, while zinc intake increased with increasing breakfast cereal consumption in 12 year old girls. There was no consistent association between intakes of micronutrients not typically added to breakfast cereal, including retinol, carotene, vitamin E, vitamin C, and copper, and breakfast cereal consumption in age-sex group (values not reported).

The percentages of Northern Ireland schoolchildren who did not meet the lower reference nutrient intake (LRNI) for micronutrients traditionally added to breakfast cereal and calcium and zinc at four levels of consumption of fortified breakfast cereal are shown in table 3. In all cases, a decreasing percentage of subjects not meeting the LRNI value was found with increasing level of consumption of fortified breakfast cereal. Vitamin D data are not given owing to the uncertainty concerning reference values for this micronutrient. ${ }^{22}$ Neither thiamin nor vitamin B-6 data are included in the table since no subject had a daily intake below the LRNI for either of these micronutrients.

Daily intakes of energy, energy yielding nutrients, and fibre at four levels of consumption of fortified breakfast cereal in Northern Ireland schoolchildren are given in table 4 . 


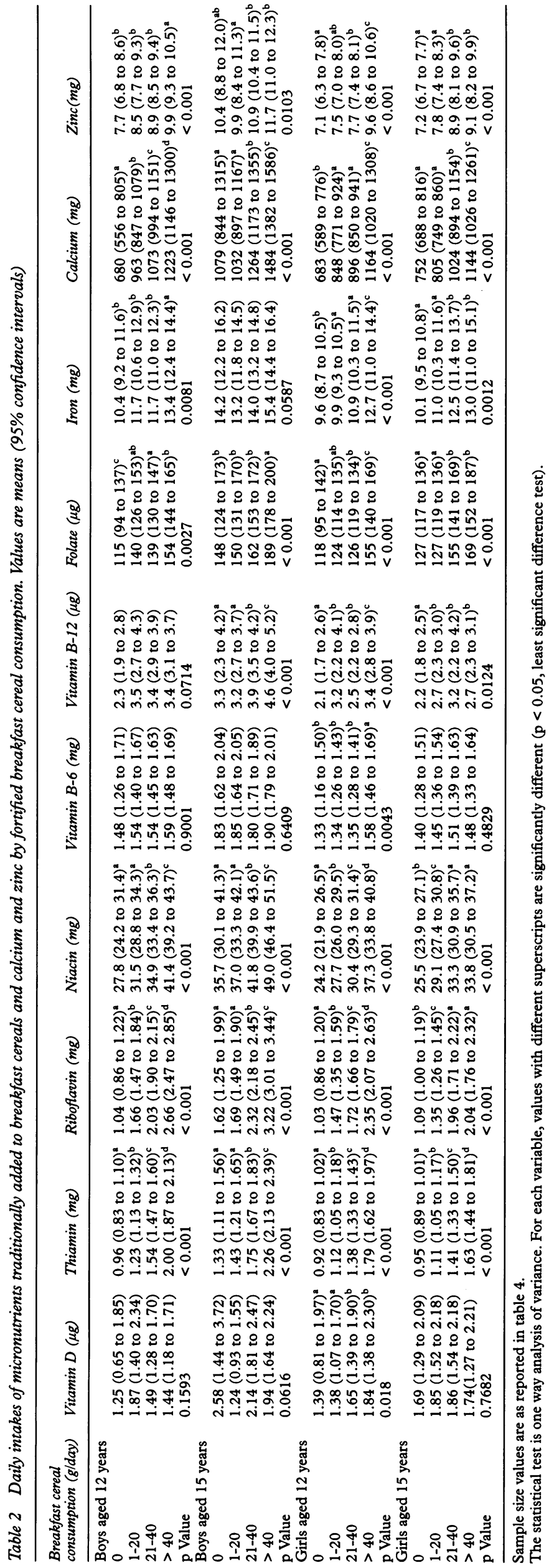

Energy intakes were not significantly different between the breakfast cereal consumption groups in 15 year olds of either sex, but 12 year old boys and girls who consumed more than 40 g/day breakfast cereal-that is, more than one serving daily - had higher energy intakes than non-consumers or those consuming lower levels. Boys (both age groups) who consumed more than $40 \mathrm{~g} /$ day breakfast cereal and younger girls who consumed more than 20 g/day breakfast cereal had significantly lower percentage contribution of fat to total energy intakes than non-consumers or those consuming lower levels of breakfast cereal. Conversely higher carbohydrate (as a percentage of total energy) intakes were generally associated with higher breakfast cereal consumption in boys and younger girls. Intake of total sugars was higher in 15 year old boys consuming more than $40 \mathrm{~g} /$ day and in 12 year old girls consuming more than $20 \mathrm{~g}$ /day breakfast cereal compared with non-consumers or those consuming lower levels. In the case of 12 year old boys and 15 year old girls, there was no significant difference in total sugars according to breakfast cereal consumption level, but starch intake was higher in both groups at levels of consumption above $40 \mathrm{~g}$ /day. Fibre intake generally increased with increasing consumption of breakfast cereal in girls and was higher in boys (both age groups) who consumed more than $40 \mathrm{~g} /$ day.

Subject and physical characteristics at four levels of consumption of fortified breakfast cereal were also assessed (table 5). A trend towards lower total cholesterol concentrations with increasing level of consumption of breakfast cereal was apparent in all groups, but significantly $(\mathrm{p}<0.001)$ so only in girls aged 12 years. Cardiorespiratory fitness as determined by maximal oxygen intake score was also greater $(p<0.04)$ in 12 year old girls who consumed breakfast cereal compared with nonconsumers. There were non-significant trends towards lower body mass index and percentage body fat with increasing level of consumption of breakfast cereal in all age-sex groups. Neither systolic nor diastolic blood pressure was significantly different between the various breakfast cereal consumption levels in any agesex group.

\section{Discussion}

The availability of data from a survey conducted in 1990/1 of a randomly selected population sample $(n=1015 ; 2 \%)$ of 12 and 15 year olds in Northern Ireland ${ }^{11}$ provided an opportunity to examine the intakes of a range of micronutrients and the importance of breakfast cereal fortification to such intakes. The macronutrient intake of this population has been previously reported ${ }^{15}$ but data on micronutrient intake are not currently available. Breakfast cereals are the only foods eaten by a substantial proportion of Northern Ireland schoolchildren which are fortified with a wide range of micronutrients. The only other commonly eaten fortified foods are those fortified with specific micronutrients only (for 
Table 3 Percentage of subjects who did not achieve the LRNI for micronutrients traditionally added to breakfast cereal and calcium and zinc by breakfast cereal consumption

\begin{tabular}{|c|c|c|c|c|c|c|c|c|c|c|c|c|c|c|c|c|}
\hline \multirow[b]{4}{*}{$\begin{array}{l}\text { Age (years) } \\
\text { Sample size }\end{array}$} & \multicolumn{16}{|c|}{ Breakfast cereal consumption (g/day) } \\
\hline & \multicolumn{4}{|l|}{0} & \multicolumn{4}{|c|}{$1-20$} & \multicolumn{4}{|c|}{$21-40$} & \multicolumn{4}{|c|}{$>40$} \\
\hline & \multicolumn{2}{|c|}{ Boys } & \multicolumn{2}{|c|}{ Girls } & \multicolumn{2}{|c|}{ Boys } & \multicolumn{2}{|c|}{ Girls } & \multicolumn{2}{|c|}{ Boys } & \multicolumn{2}{|c|}{ Girls } & \multicolumn{2}{|c|}{ Boys } & \multicolumn{2}{|c|}{ Girls } \\
\hline & $\begin{array}{l}12 \\
11\end{array}$ & $\begin{array}{l}15 \\
20\end{array}$ & $\begin{array}{l}12 \\
31\end{array}$ & $\begin{array}{l}15 \\
49\end{array}$ & $\begin{array}{l}12 \\
42\end{array}$ & $\begin{array}{l}15 \\
29\end{array}$ & $\begin{array}{l}12 \\
67\end{array}$ & $\begin{array}{l}15 \\
85\end{array}$ & $\begin{array}{l}12 \\
95\end{array}$ & $\begin{array}{l}15 \\
95\end{array}$ & $\begin{array}{r}12 \\
106\end{array}$ & $\begin{array}{l}15 \\
60\end{array}$ & $\begin{array}{l}12 \\
89\end{array}$ & $\begin{array}{l}15 \\
94\end{array}$ & $\begin{array}{l}12 \\
34\end{array}$ & $\begin{array}{l}15 \\
27\end{array}$ \\
\hline Riboflavin & 18 & 15 & 35 & 20 & 0 & 0 & 3 & 6 & 1 & 0 & 0 & 0 & 0 & 0 & 0 & 0 \\
\hline Niacin & 18 & 20 & 13 & 8 & 5 & 0 & 3 & 2 & 0 & 1 & 1 & 0 & 0 & 0 & 3 & 4 \\
\hline Folate & 100 & 75 & 94 & 96 & 90 & 86 & 93 & 95 & 89 & 82 & 93 & 80 & 85 & 57 & 76 & 70 \\
\hline Iron & 0 & 0 & 35 & 20 & 0 & 0 & 22 & 17 & 1 & 0 & 13 & 8 & 0 & 0 & 11 & 4 \\
\hline Calcium & 18 & 10 & 32 & 4 & 0 & 0 & 9 & 3 & 0 & 0 & 4 & 0 & 0 & 0 & 3 & 0 \\
\hline Zinc & 0 & 0 & 23 & 2 & 7 & 0 & 7 & 0 & 2 & 0 & 8 & 2 & 0 & 1 & 0 & 0 \\
\hline
\end{tabular}

No subject had a daily intake of thiamin or vitamin B-6 that was below the LRNI. Vitamin D data are not shown because of the uncertainty concerning reference values. ${ }^{22}$

example wheat flour with calcium, iron, thiamin, niacin; margarine with vitamin $\mathrm{A}$ and vitamin D).

Mean micronutrient intakes of this population were generally well above reference values, ${ }^{22}$ with the exception of folate intake which fell well below the estimated average requirement (EAR) in all age-sex groups apart from boys aged 15 years, and iron intake (well accepted to be a problem in girls), ${ }^{8}$ which fell below the EAR for females of both age groups.

The proportion of Northern Ireland adolescents habitually consuming fortified breakfast cereal in the present study ( $94 \%$ boys, $83 \%$ girls) was higher than that previously reported in 14-16 year old adolescents in Nottinghamshire ( $71 \%$ boys, $46 \%$ girls $)^{23}$ and in a sample of 5000 adolescents aged 16-17 years throughout Great Britain (79\% boys, $63 \%$ girls) ${ }^{24}$ This may be due to the younger age group of subjects in the present study and an apparent trend towards decreased consumption of breakfast cereal in older adolescents, ${ }^{8}$ but may also reflect regional differences in dietary practices. Comparison of daily intakes of micronutrients traditionally added to breakfast cereals in non-consumers compared with consumers of fortified breakfast cereal shows significantly higher values among the latter. In many cases micronutrient intakes increased significantly with increasing level of consumption of fortified breakfast cereal. This finding cannot be explained simply in terms of overall higher energy intakes with increased breakfast cereal consumption since the finding was observed in 15 year old boys and girls whose overall energy intakes were not significantly different when consumers and non-consumers were compared, or when energy values at different levels of breakfast cereal consumption were compared.

Although intakes of most micronutrients in this population appear adequate when expressed as mean values, appreciable proportions of those Northern Ireland schoolchildren who did not consume fortified breakfast cereal had daily intakes below the LRNI for individual micronutrients (riboflavin, 23\%; niacin, $13 \%$; vitamin B-12, $8 \%$; folate, $92 \%$; iron (girls), 26\%; calcium, 14\%; zinc (girls), 10\%). The LRNI of any nutrient is the amount estimated to meet the needs of the bottom 3\% of the population; if individuals are habitually eating less than the LRNI they will almost certainly be deficient. ${ }^{22}$ For most micronutrients the percentage of subjects with overall intakes below the LRNI decreased with increasing level of consumption of fortified breakfast cereal; among those consuming $20 \mathrm{~g} /$ day or more - that is, at least one serving of breakfast cereal daily - few subjects with such low daily intakes were found. This clearly demonstrates the potential of fortification to benefit those subjects consuming diets of low/marginal nutritional quality. The exceptions were folate (in all age-sex groups) and to a lesser extent iron (in younger girls in particular), for which high proportions of subjects had intakes falling below the LRNI despite consuming high levels of fortified breakfast cereal, as reflected in the low mean intakes of these nutrients.

Evidence that these observations reflect real effects of fortification and are not simply the result of an overall dietary pattern for which breakfast cereal consumption is a marker is supported by data on the intakes of micronutrients such as retinol, carotene, vitamin $\mathrm{E}$, and vitamin $\mathrm{C}$, not usually added to breakfast cereal during fortification, which showed no significant differences when examined according to breakfast cereal consumption level in any age-sex group (not shown). Since fortified breakfast cereals are consumed with milk it is not possible to separate the dietary effects of the two foods by this type of analysis; high consumers of breakfast cereal almost certainly also consume high milk levels. Thus the significant increases in intakes of nutrients such as calcium and zinc according to breakfast cereal consumption level are most likely due to the milk consumed with them, since breakfast cereals are not typically fortified with, or naturally rich in, these nutrients. Likewise the association demonstrated between fortified breakfast cereal consumption and riboflavin intake probably reflects the dietary composition of both foods.

The public health rationale for fortification (the addition of nutrients to a food to levels above those normally present in that food) is that additional intakes of nutrients may be beneficial in population groups. ${ }^{25}$ The question of folic acid fortification has received much attention recently following the publication of conclusive evidence of the effectiveness of the vitamin in the prevention of neural tube defects 


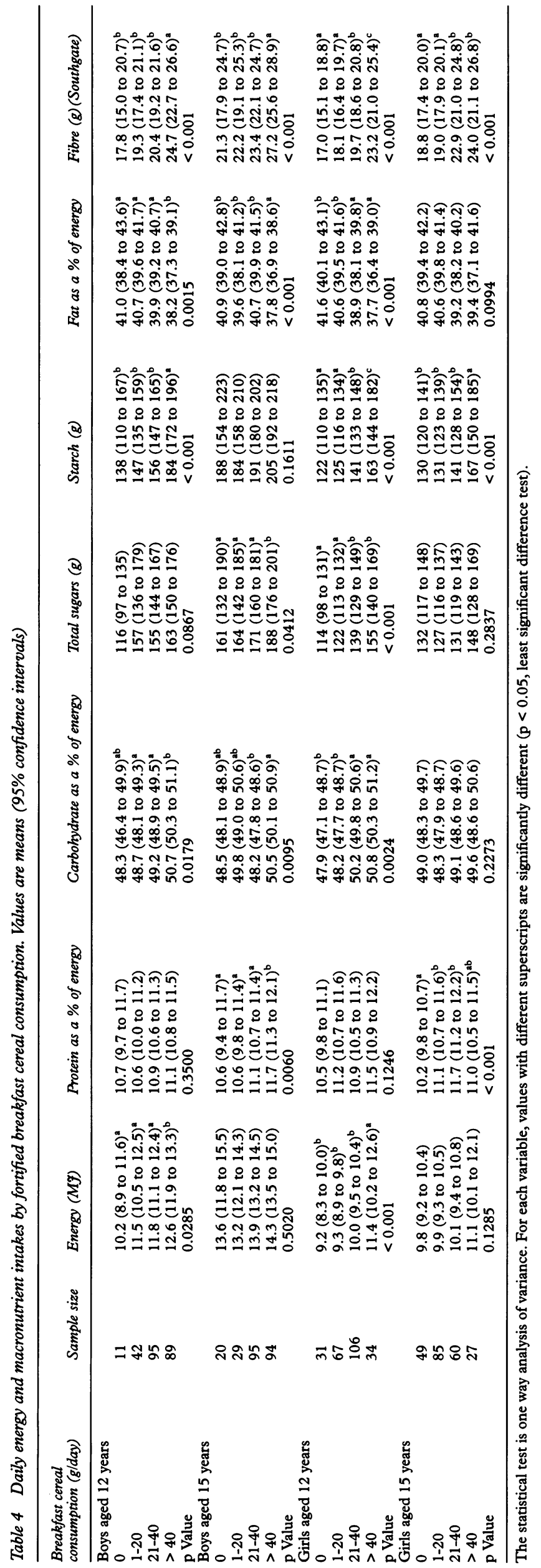

(NTDs). ${ }^{26}$ Although the mechanism(s) involved are still under investigation, and also appear to involve an independent role for vitamin $B-12,{ }^{27}$ such findings have led to the generation of new folic acid recommendations by the UK Department of Health. ${ }^{10}$ These recommendations are almost identical with those published by other national authorities in the USA and Australia. ${ }^{28} 29$ The recommendation for the prevention of first occurrence of NTDs in women with no previous history (representing $95 \%$ of all cases) is $400 \mu \mathrm{g} /$ day folic acid, over and above current intakes of the vitamin. ${ }^{10}$ Folic acid fortification offers the most promising means of ensuring that the recommended levels are reached by the target populationthat is, all women of child bearing age-since increasing natural food folate sources alone would require a threefold increase in current folate intakes. ${ }^{30}$ Moreover, even when a significant increase in food folate intake is achieved experimentally, it has recently been shown to be relatively ineffective (compared with supplements and fortified food) at increasing erythrocyte folate status, probably because of the poorer bioavailability of the vitamin when present in the polyglutamate (food folate) form. ${ }^{31}$ Supplementation with folic acid, although effective, is unlikely to reach a major proportion of those who need it. ${ }^{32}$ In the present study the folate intakes of female adolescents $(114$ and $121 \mu \mathrm{g} /$ day in 12 and 15 year olds respectively) fell far short of recommended levels, failing even to achieve the reference value of $200 \mu \mathrm{g} /$ day which was set before the publication of the new folic acid recommendations specific to the prevention of NTDs. ${ }^{10}$ There is cause for concern in this regard since most teenage pregnancies are unplanned (therefore folic acid supplementation before conception is unlikely to be in place), and the incidence of NTDs, which is particularly high in Northern Ireland, ${ }^{33}$ appears to be higher in younger (and older) mothers than the general population of women in their reproductive years. ${ }^{10}$ The fact that folate intakes increased significantly with increasing consumption of fortified breakfast cereal demonstrates the potential of fortification to make a valuable contribution to overall folate intakes, but clearly current levels of fortification are not high enough to ensure that the recommended increased intakes are reached by this vulnerable group. The present study therefore supports recent arguments ${ }^{34}$ for a public health initiative to include a more aggressive approach to folic acid fortification. New evidence on the role of folic acid ${ }^{35}$ (and to a lesser extent vitamins B-6 and $\mathrm{B}-12)^{36}$ in lowering plasma homocysteine level, an independent risk factor for coronary heart disease in the general population, is likely to strengthen the arguments for fortification with these micronutrients.

Any potential benefit of consumption of fortified breakfast cereal on micronutrient intake would be irrelevant if it resulted in a dietary pattern that was in conflict with current recommendations for the prevention of chronic disease. $^{34}$ Thus the extent to which breakfast cereal consumption patterns of Northern 


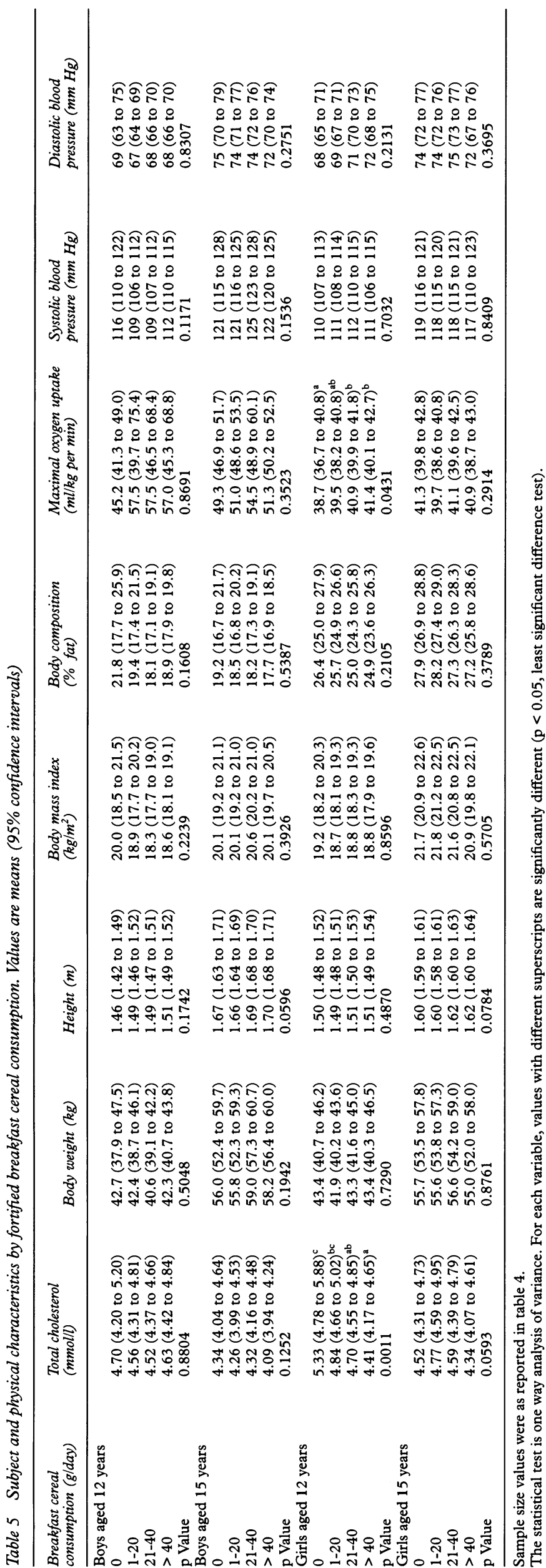

Ireland schoolchildren relate to macronutrient intake and health indices was also examined in the present study. Fat as a percentage of dietary energy has previously been reported for this population to be high at $39 \%,{ }^{15}$ and considerably above current Department of Health ${ }^{34}$ recommendations of $35 \%$. Although none of the breakfast cereal consumption subgroups met the recommendation, the finding that fat intake of this population decreased with increasing consumption of breakfast cereal is consistent with other studies. ${ }^{24} 3738$ Corresponding increases in carbohydrate (as a percentage of dietary energy), starch, and fibre were shown to be associated with increased breakfast cereal consumption, generally conforming with the recommendation of increasing intake of complex carbohydrates as a means of achieving a reduction in fat as a percentage of total energy. ${ }^{4}$ The consumption of fortified breakfast cereal in the present study was not consistently associated with increased intake of total sugars; thus the increase in carbohydrate energy associated with breakfast cereal consumption cannot be explained by increased sugars alone. The trends in subject and physical characteristics such as body mass index, percentage body fat, and cholesterol level, which tended to decrease with increased consumption of breakfast cereal, may be the indirect result of the inverse relationship between fat energy and breakfast cereal level. Alternatively these trends may simply be a reflection of a general dietary and lifestyle pattern for which breakfast cereal consumption is a marker. In any case, with the exception of cholesterol levels in 12 year old girls, none of these trends was significant. Support for concerns that the sodium content of some manufactured food may contribute to elevated blood pressure ${ }^{4}$ was not evident in the case of breakfast cereals in the present investigation in which there were no significant differences in systolic or diastolic blood pressure associated with the consumption of breakfast cereal.

In conclusion, although mean micronutrient intakes of Northern Ireland adolescents generally appear to be adequate, there is cause for concern in the case of low folate intake (in both boys and girls) and low iron intake in girls. Fortified breakfast cereals, which are consumed by a high percentage of Northern Ireland schoolchildren, appear to make a significant contribution to micronutrient intakes, particularly in subjects consuming diets of poor nutritional quality. Effects on macronutrient intakes associated with breakfast cereal consumption are consistent with current dietary recommendations.

This study was supported by the Northern Ireland Chest, Heart and Stroke Association, the Department of Health and Social Services (Northern Ireland), and Kellogg Company of Great Britain Ltd. In addition the contribution of the following people to the data collection in the original survey is gratefully acknowledged: Paula Robson, Elizabeth Archer, and Hilary Morrison (dietary data); Craig Mahoney (fitness testing); Daphne Primrose (medical aspects).

1 Lauer RM, Lee J, Clarke WR. Factors affecting the relationship between childhood and adult cholesterol levels: the Muscatine Study. Pediatrics 1988;82:310-28. 
2 Webber LS, Srinivasan SR, Wattingey WA, Berenson GS. Tracking of serum lipids and lipoproteins from childhood to adulthood: the Bogalusa heart study. Am $₹$ Epidemiol 10 adulthood: the

3 Department of Health. Health of the nation: $a$ strategy for health in England. London: HMSO, 1992.

4 Department of Health. Report on Health and Social Subjects No 46. Nutritional aspects of cardiovascular disease. London: HMSO, 1994.

5 Adamson A, Rugg-Gunn A, Butler NR, et al. Nutritional intake, height and weight of 11 and 12 year old Northumbrian children in 1990 compared with information obtained in 1980. Br $\mathcal{F}$ Nutr 1992;68:543-63.

6 McNeill G, Davidson L, Morrison DC, et al. Nutrient intake in schoolchildren: some practical considerations. Proc Nutr Soc 1991;50:37-43.

7 Robson P, Strain J,, Cran GW, et al. Snack energy and nutrient intakes of Northern Ireland adolescents. Proc Nutr Soc 1991;50:180A

8 Department of Health. Report on Health and Social Subjects No 36. The diets of British schoolchildren. London: HMSO, 1989.

9 Hill A Causes and consequences of dieting and anorexia. Proc Nutr Soc 1993;52:211-8.

10 Department of Health. Report from an expert advisory group. Folic acid and the prevention of neural tube defects. London:

11 Boreham C, Savage JM, Primrose D, et al. Coronary risk factors in schoolchildren. Arch Dis Child 1993;68:182-6.

12 Durnin JVGA, Rahaman MM. The assessment of the amount of fat in the human body from measurements of skinfold thickness. Br $\mathcal{F}$ Nutr 1967;21:681-9.

13 Boreham CAG, Paliczka VJ, Nicols AK. A comparison of the PWC170 and 20-MST tests of aerobic fitness in adolescent schoolchildren. $\mathcal{F}$ Sports Med Phys Fitness 1990; 30:19-23.

14 Riddoch C. Northern Ireland health and fitness survey. A report by the Division of Physical and Health Education, The Queen's University of Belfast, 1990.

15 Strain J, Robson PJ, Livingstone MBE, et al. Estimates of food and macronutrient intake in a random sample of food and macronutrient intake in a random sample of

16 van Stavern WA, de Boer JD, Burema J. Validity and van Stavern WA, de Boer $J$, Burema usual food intake during one month. Am $\mathcal{F}$ Clin Nutr 1985; 42:554-9.

17 Lee P, Cunningham K. Irish national nutrition survey. Dublin: The Irish Nutrition and Dietetic Institute, 1990.

18 Crawley H. Food portion sizes. London: HMSO, 1988

9 Livingstone MBE, Prentice AM, Coward WA, et al. Validation of estimates of energy intake by weighed dietary record and diet history in children and adolescents. Am $\mathcal{F}$ Clin Nutr 1992;56:29-35.

20 Goldberg GR, Black AE, Jebb SA, et al. Critical evaluation of energy intake data using fundamental principles of energy physiology. 1. Derivation of cut-off limits to identify under-recording. Eur $\mathcal{F}$ Clin Nutr 1991;45;569-81.

21 Black AE, Goldberg GR, Jebb SA, et al. Critical evaluation of energy intake data using fundamental principles of energy physiology. 2. Evaluating the results of published surveys. Eur f Clin Nutr 1991;45:583-99.

22 Department of Health. Report on Health and Social Subjects No 41. Dietary reference values for food energy and nutrients for the United Kingdom. London: HMSO, 1991

23 Lund BK, Gregsun K, Neale RJ, Tilston CH. The breakfast arrangements of schoolchildren. Food Marketing Group, University of Nottingham, 1990.

24 Crawley HF. The role of breakfast cereals in the diets of 16-17 year old teenagers in Britain. Fournal of Human Nutrition and Diet 1993;6:205-16.

25 British Nutrition Foundation. Briefing paper. Food fortification. London: The British Nutrition Foundation, 1994.

26 MRC Vitamin Study Research Group. Prevention of neural tube defects: results of the Medical Research Council vitamin study. Lancet 1991;338:131-7.

27 Kirke PN, Molloy AM, Daly LE, et al. Maternal plasma folate and vitamin B-12 are independent risk factors for neural tube defects. $Q \mathcal{F ~ M e d ~ 1 9 9 3 ; 8 6 : 7 0 3 - 8 . ~}$

28 US Department of Health and Human Services, Centers for Disease Control and Prevention. Recommendations for the use of folic acid to reduce the number of cases of spina bifida and other neural tube defects. MMWR Morbid Mortal Wkly Rep 1992;41:1-7.

29 National Health and Medical Research Council. Revised statement on the relationship between dietary folic acid and neural tube defects such as spina bifida. 115th session. Australia: NHMRC, 1993.

30 Gregory J, Foster $\mathrm{K}$, Tyler $\mathrm{H}$, Wiseman $\mathrm{M}$. The dietary and nutritional survey of British adults. London: HMSO, 1990.

31 Cuskelly GJ, McNulty H, Scott JM. Effect of increasing dietary folate on red-cell folate: implications for the prevention of neural tube defects. Lancet 1996;347:657-9.

32 Clark MA, Fisk NM. Minimal compliance with Department of Health recommendation for routine folate prophylaxis to prevent

33 Eurocat Working Group. Prevalence of neural tube defects in 20 regions of Europe and the impact of prenatal diagnosis, 1980-1986. I Epidemiol Community Health 1991;45:528.

34 Wald NJ, Bower C. Folic acid and the prevention of neural tube defects. $B M$ F 1995;310:1019-20.

35 Boushey CJ, Beresford SAA, Omenn GS, et al. A quantitative assessment of plasma homocysteine as a risk factor for vascular disease. $\mathscr{F} A M A$ 1995;274:1049-57.

36 Ubbink JB, Vermaak WJH, van der Merwe A, Becker PJ. Vitamin B-12, vitamin-B-6, and folate nutritional status in men with hyperhomocysteinaemia. Am $₹$ Clin Nutr 1993;57:47-53.

37 Jenkins DJA, Wolever TMS, Vuksan V, et al. Nibbling versus gorging: metabolic advantages of increased meal frequency. N Engl F Med 1989;321:929-34.

38 Gibson SA, O'Sullivan KR. Breakfast cereal consumption patterns and nutrient intakes of British schoolchildren. $\mathcal{F} R$ Soc Health 1995;115:366-70. 